\title{
A CLINICAL STUDY OF EARLY BREAST CARCINOMA AND ITS MANAGEMENT
}

\author{
Kaushik Vora1, Ranjit Kr. Deka², Rakesh Roshan ${ }^{3}$
}

1 Postgraduate Trainee, Department of General Surgery, Gauhati Medical College, Assam.

2 Professor, Department of General Surgery, Gauhati Medical College, Assam.

3 Postgraduate Trainee, Department of General Surgery, Gauhati Medical College, Assam.

\section{BACKGROUND}

ABSTRACT

Breast Carcinoma is the most common malignancy among Indian women ${ }^{1}$ and the leading cause for carcinoma related death in women. According to GLOBOCAN 2012, India along with United States and China collectively accounts for almost one-third of the global breast cancer burden. In India for the year 2012 - 144,937 women were newly detected with breast cancer and 70,218 women died of breast cancer. India is facing challenging situation due to $11.54 \%$ increase in incidence and $13.82 \%$ increase in mortality due to breast cancer during $2008-2012.2,3$

Aims and Objectives- To identify various risk factors associated with breast carcinoma, age, parity, menarche, menopause etc., various clinical presentations and also various modes of management.

\section{MATERIALS AND METHODS}

Study Design- It is a descriptive study done in Gauhati Medical College and Hospital in the Dept. of Surgery from 1 st July 2016 to $31^{\text {st }}$ June 2017 on 54 patients. The clinical study was carried out in patients admitted in Gauhati Medical College and Hospital during the period from $1^{\text {st }}$ July 2016 to $30^{\text {th }}$ June 2017. All patients were diagnosed with early breast carcinoma Stage I, IIa or IIb clinically or by imaging methods were included in the study. The data is represented and expressed in percentage and graphs.

\section{RESULTS}

The youngest woman in our study was 28 years old and oldest 65 years. In the present series, $12.9 \%$ of the patients attained menarche at the age of 11 yrs. or below, $77.6 \%$ of the patients were in the age group $(12,13$ or 14 yrs.), only $9.2 \%$ of the patients attained menarche at 15 yrs. or above. $98 \%$ of the patients had breast-fed their children for more than 6 months in our study. $9 \%$ of the patients had a family history of breast cancer in either first- or second-degree relatives. All the cases presented to us with history of lump in the breast. The next common symptom was pain followed by axillary mass. $42 \%$ of the cases presented with tumour size of $2-5 \mathrm{~cm}$ with axillary node positive, and only $11 \%$ of the cases with tumour size $<2 \mathrm{~cm}$ was positive for axillary node. In the present study, sensitivity for FNAC procedures was $66 \%$ and for Tru-Cut biopsy was $90 \%$. In the present series, only $18 \%$ of the patients underwent Breast Conserving Surgery, majority of them underwent MRM, Auchincloss type. ER status was found to be positive in $51 \%$ of patients and PR status was positive in $50 \%$ of cases. Post-operatively, $78 \%$ of our cases were discharged without any significant complications.

\section{CONCLUSION}

The mean age of presentation for breast carcinoma in the present study was a decade earlier compared to western patients. Most of the breast cancers are sporadic rather than familial. $100 \%$ of the patients presented with lump in the breast. Upper outer quadrant is the common site for breast cancer due to greater amount of breast tissue in the upper outer quadrant. The finding of present series strengthens the notion that the likelihood of axillary involvement is directly related to the size of the primary tumour. Most cases of early breast cancer belonged to Stage IIB. 50\% of the patients had ER/PR positive, reflecting an overall low positivity rate when compared to western studies. Majority of the patients underwent Modified Radical Mastectomy as surgical treatment. The comparatively low take-up rate of BCS may relate to factors such as social and economic circumstances.

\section{KEYWORDS}

Early Breast Carcinoma.

HOW TO CITE THIS ARTICLE: Vora K, Deka RK, Roshan R. A clinical study of early breast carcinoma and its management. J. Evolution Med. Dent. Sci. 2018;7(11):1333-1336, DOI: 10.14260/jemds/2018/303

\section{BACKGROUND}

Early Breast Carcinoma is defined as "Tumour of not more

than $5 \mathrm{~cm}$ in diameter with either palpable or impalpable axillary lymph node, but not fixed and no evidence of distant

'Financial or Other Competing Interest': None.

Submission 03-02-2018, Peer Review 27-02-2018,

Acceptance 06-03-2018, Published 12-03-2018.

Corresponding Author:

Kaushik Vora,

South Sarania, Ashram Road,

Byelane-3,

Ulubari, Guwahati-781007, Assam.

E-mail: geilkaushik@gmail.com

DOI: $10.14260 /$ jemds $/ 2018 / 303$ metastasis or by TNM classification it includes Stage I, IIa or IIb."

Breast Carcinoma is the most common malignancy among Indian women, 1 and the leading cause for carcinoma related death in women. According to GLOBOCAN 2012, India along with United States and China collectively accounts for almost one-third of the global breast cancer burden. In India for the year 2012, 144,937 women were newly detected with breast cancer and 70,218 women died of breast cancer. India is facing challenging situation due to $11.54 \%$ increase in incidence and $13.82 \%$ increase in mortality due to breast cancer during 2008 - 2012.2,3 The main reasons for this observed hike in mortality is due to lack of inadequate breast cancer screening, diagnosis of disease at advanced stage and 
unavailability of appropriate medical facilities. Increasing urbanisation and westernisation associated with changing lifestyle and food habits has led breast cancer to attain top position in all major urban registries, although cervical cancer still remains the most common cause in rural India. 4

As carcinoma breast is quite a common problem encountered in surgical practice, this study attempts to identify various risk factors, modes of presentation and various treatment modalities.

\section{Aims and Objectives}

1. Aim of the present study is to study various risk factors like- Age, Parity, Breast feeding, Menstrual history, Family history and Alcohol intake.

2. To study various modes of clinical presentation.

3. To study various modes of treatment, surgical management included.

\section{MATERIALS AND METHODS}

\section{Study Design}

It is a descriptive study done in Gauhati Medical College and Hospital in the Dept. of Surgery from 1st July 2016 to 31 st June 2017 on 54 patients.

\section{Inclusion Criteria}

All patients diagnosed with Early Breast Carcinoma Stage I, IIa or IIb clinically or by imaging methods.

\section{Exclusion Criteria}

1. Any associated cardiovascular disease or renal insufficiency or Chronic Liver disease.

2. History of other malignancy, which could affect compliance with the protocol or interpretation of results.

3. Previous neoadjuvant or adjuvant breast cancer treatment.

4. Collagen Vascular Disease.

\section{Method of Collecting Data}

- The patients selected for this study were those who were proven cases of early carcinoma breast.

- The clinical study was done by interviewing, clinical examination and by doing relevant investigations as required and treated depending upon the stage and severity of the disease.

- Particular attention was given to various modes of presentation, menstrual, obstetric and family history and also personal history.

- The patients were surgically treated with Lumpectomy or Total Mastectomy or Modified Radical Mastectomy and also by chemotherapy, radiotherapy and hormonal therapy as indicated.

Each case was followed up till the end of study. Follow-up included examination for recurrence of the tumour at the operated site, in the axilla and distant metastasis. Follow-up was also done for post-operative complications.

\section{Statistical Method}

The data is represented and expressed in percentage and graphs.

\section{RESULTS}

In the present series, the youngest patient was 28 years old and the oldest patient was 65 years old. The percentage of cases increased with age reaching a plateau between $30-49$ years and thereafter the incidence decreased (Table 1).

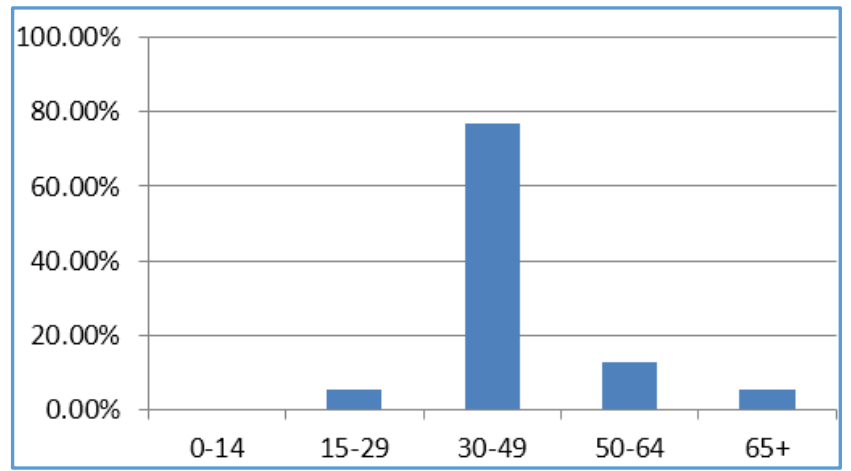

Table 1

In the present series, $76 \%$ of patients had menarche between 12 - 14 yrs. of age group. Only $12.9 \%$ of the patients attained menarche at 11 or below 11 yrs. of age.

$98 \%$ of the cases breastfed their children for more than 6 months. Percentage of cases with family history of breast cancer was $9 \%$ in the present study. In our present series, $100 \%$ of the patients presented with a history of breast lump followed by pain and axillary lump. $22 \%$ of the cases presented with breast pain and $7.4 \%$ of the patient presented with axillary lump (Table 2 ).

In the present study, only $9 \%$ of the patients had their age at first birth below 20 yrs. of age, which was similar to Adami $\mathrm{H}^{5}$ series and MacMahon ${ }^{6}$ series. $35 \%$ of the patients had their age at first birth in $20-24$ yrs. of age group. Only $9 \%$ of the patients had their age at first birth > 35 yrs. of age. Analysis of the association between age at first and relative risk of breast cancer could not be done due to absence of a control group.

In the present series only $6 \%$ of the patients were nulliparous. Das $\mathrm{S}^{7}$ series, an Indian study also reported only $5.21 \%$ in the nulliparous group. The less number of nulliparous cases in the present study might be due to the age old tradition in Indian subcontinent of getting girls married at an younger age and families almost invariably opting for children.

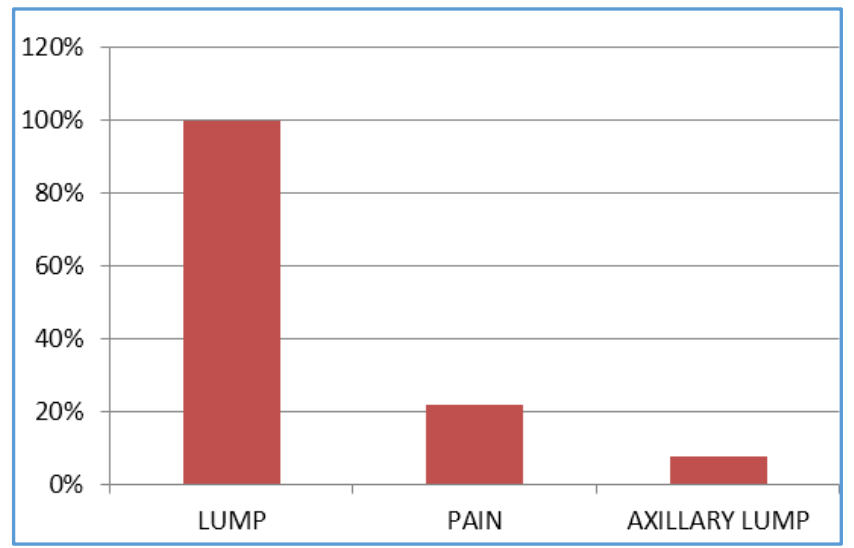

Table 2 
In the present series, 16 cases were 'clinically detected' (as detected by imaging studies (excluding lymphoscintigraphy) or by clinical examination) as $\mathrm{N} 1$ positive. Out of 16 only 1 patient had tumour size $<2 \mathrm{~cm}$, rest all were in the tumour size of $2-5 \mathrm{~cm}$ group. $42 \%$ of the cases in the tumour size of $2-5 \mathrm{~cm}$ were axillary node positive and only $11 \%$ of the cases with tumour size $<2 \mathrm{~cm}$ was positive for axillary node (Table 3).

\begin{tabular}{|c|c|c|c|}
\hline $\begin{array}{c}\text { Tumour } \\
\text { Size }\end{array}$ & $\begin{array}{c}\text { No. of Cases with } \\
\text { Axillary Node in } \\
\text { Present Series }\end{array}$ & $\begin{array}{c}\text { Total } \\
\text { No. of Cases }\end{array}$ & $\begin{array}{c}\text { Percentage } \\
\text { of Cases in } \\
\text { Present Series }\end{array}$ \\
\hline$<2 \mathrm{~cm}$ & 1 & 9 & $11 \%$ \\
\hline $2-5 \mathrm{~cm}$ & 15 & 35 & $42 \%$ \\
\hline \multicolumn{3}{|c|}{ Table 3 } \\
\hline
\end{tabular}

Incidence of breast cancer was $51 \%$ on the left side and $49 \%$ on the right side. In our series Upper-Outer quadrant showed the maximum incidence of breast cancer. During the study $39 \%$ of the patients presented with history of $3-6$ months, $33 \%$ of the patients with $1-3$ months and $11 \%$ of the cases presented with $6-12$ months of history. Sensitivity for FNAs interpreted as malignant was $66 \%$ compared with $90 \%$ for core biopsy, indicating a significantly greater sensitivity for core biopsy.

\section{Management}

In the treatment perspective, modified radical mastectomy was done in $82 \%$ of the cases and the remaining cases underwent Breast Conservation Surgery (Lumpectomy + Axillary lymph node dissection). Chemotherapy was given to all the cases post-operatively. Patients received 4 cycles of Adriamycin and Cyclophosphamide followed by 4 cycles of Paclitaxel. Patients were referred to Cancer Institute for Radiotherapy. Radiation therapy was given to all the 10 patients who underwent BCS. In the treatment group of MRM which consisted of 44 patients, 32 patients received Radiotherapy. The patients who did not receive RT were having negative axillary nodes, tumour $<5 \mathrm{~cm}$ and negative margin $>5 \mathrm{~mm}$.

ER/PR positive pre-menopausal and post-menopausal patients were given tamoxifen and aromatase inhibitors respectively. HER2 positive patients received Trastuzumab additionally.

Post-operatively, $78 \%$ of our cases were discharged without any significant complications. Only about $10 \%$ of cases had seroma at the operative site, which regressed after aspiration. Wound infection was seen in $5 \%$ of the cases, graft failure in $3.7 \%$ of the cases and $1.8 \%$ of the patients had UTI.

$92 \%$ of the cases presented with Invasive Ductal Carcinoma, $4 \%$ with Invasive Lobular carcinoma. In the present study, ER status were positive in $51 \%$ of patients and PR status was positive in $50 \%$ of patients. HER-2/neu receptor was positive in $27 \%$ of the patients. Triple negative breast cancer was seen in $24 \%$ of the cases. Similar findings were seen in Patnayak R series. In the post-operative period seroma complication was seen in $9.2 \%$ of the patients, $5 \%$ with superficial wound infection, $3.7 \%$ with graft failure and $1.8 \%$ had UTI.

\section{DISCUSSION}

$77 \%$ of patients were between 30 - 49 years' age group far greater than seen in Sharma J ${ }^{8}$ and Sen $^{9}$ series. The reason might be due to genuine rise in incidence of breast cancer in young women. Breast cancer incidence is increasing even in the older patient. It is just that increase in younger population is more than that in older population, may be because of the predominant young population in India.

In the present series, $12.9 \%$ of the patients attained menarche at the age of $11 \mathrm{yrs}$. or below, $77.6 \%$ of the patients were in the age group (12, 13 or 14 yrs.), only $9.2 \%$ of the patients attained menarche at 15 yrs. or above. Similar findings were seen in the study of collaborative group on Hormonal Factors in Breast Cancer ${ }^{10}$ and Das $\mathrm{S}^{7}$ series. Since, there was no Control group (Women without breast cancer) with same spectrum of age distribution of menarche valid comparisons between the two groups cannot be done and any analytical method to calculate.

In the present series of 51 parous cases $98 \%$ of the patients had breast-fed their children for more than 6 months, which was comparable to other Indian study, Das $\mathrm{S}^{7}$ series. We could not establish the relationship between the protective effects of lactation for breast cancer in our study as breast feeding is a near universal practice in India and continues for most children beyond infancy. In our series, 9\% of the patients had a family history of breast cancer in either first or second-degree relatives. The incidence of familial breast cancer was almost similar in all the three studies. Higher number of presentation with breast lump can be attributed to absence of screening modalities, affordable diagnostic tests and lack of awareness among population of lower socio-economic class. $42 \%$ of the cases in the tumour size of $2-5 \mathrm{~cm}$ were Axillary node positive, and only $11 \%$ of the cases with tumour size $<2 \mathrm{~cm}$ was positive for axillary node. One of the reasons for lesser number of axillary node positive in $2-5 \mathrm{~cm}$ group in our series would be case selection bias. Since the study was restricted to Stage I and II breast cancer, no patient with $\mathrm{T} 2$, N2 or T2N3 breast cancer was included in the study.

The comparatively low take-up rate of BCS in the present study may relate to factors such as social and economic circumstances, (long post-operative radiotherapy follow-up), limited resources, although concern over the increased risk of relapse and metastasis seems to have been the primary consideration for both breast cancer patients and their doctors. Also younger age itself however was also shown to be associated with diverse, aggressive and pathological features. ${ }^{11}$

Our finding of an overall positivity rate for ER and PR is lower than that reported in western literature Li CI series, ${ }^{12}$ but consistent with studies on Indian patients. The high proportion of receptor negative cases can be partially explained by the younger age of our patients or due to racial differences. Breast cancer at younger age has been associated with high tumour proliferation, higher tumour grade or "basal-like" tumours. ${ }^{13}$

\section{CONCLUSION}

The mean age of presentation for breast carcinoma is a decade earlier in the present study compared to western patients. 
Early age of menarche as a risk factor for breast cancer could not be proved. Due to absence of control group, relative risk for breast cancer per 1 year younger at menarche could not be assessed. Nulliparity as risk factor for breast-cancer could not be established in this study, as this group comprised of only $7 \%$ of the total patients and also absence of a control group to calculate relative risk.

Since breast feeding is a near universal practice in India, in the absence of a comparison group (non-breast-feeding breast cancer patient), an inference regarding the protective action of breast feeding could not be determined. Most of the breast cancers are sporadic rather than familial.

$100 \%$ of the patients presented with lump in the breast, which was probably due to absence of breast cancer screening program, affordable diagnostic tests and lack of awareness among population of lower socio-economic class. The finding of present series strengthens the notion that the likelihood of axillary involvement is directly related to the size of the primary tumour.

Most cases of early breast cancer belonged to Stage IIB. The reason moves around the two major factors, non-existent of breast cancer screening program and non-participation of women if any such program do exist. This is due to unawareness, lack of access to healthcare facilities and socialcultural attitudes. Hence, by educating the masses on selfbreast examination and screening techniques, they can detect their disease themselves which could also help in early diagnosis of the disease. Infiltrating ductal carcinoma was the commonest histopathological type, none of the patients were diagnosed as DCIS or LCIS.

For the diagnosis of breast carcinoma, core needle biopsy was done in majority of the patients and a positive predictive outcome was obtained in most of them. FNAC was done in those patients whose tumour size was comparatively less.

Finally, in order to reduce the burden of breast cancer, a multi-sectoral approach and evidence-based strategies aiming at early detection and effective management of the disease should be implemented. Hence, public health programs that ensure access to appropriate, affordable diagnostic tests and treatment must be introduced.

\section{REFERENCES}

[1] Malvia S, Bagadi SA, Dubey US, et al. Epidemiology of breast cancer in Indian women. Asia Pac J Clin Oncol 2017;13(4):289-95.
[2] Ferlay J, Shin HR, Bray F, et al. Estimates of worldwide burden of cancer in 2008: GLOBOCAN 2008. Int J Cancer 2010;127(12):2893-917.

[3] Ferlay J, Soerjomataram I, Dikshit R, et al. Cancer incidence and mortality worldwide: sources, methods and major patterns in GLOBOCAN 2012. Int J Cancer 2015;136(5):E359-E86.

[4] Kaarthigeyan K. Cervical cancer in India and HPV vaccination. Indian J Med Paediatr Oncol 2012;33(1):7-12.

[5] Adami HO, Hansen J, Jung B, et al. Age at first birth, parity and risk of breast cancer in a Swedish population. Br J Cancer 1980;42(5):651-8.

[6] MacMahon B, Cole P, Lin TM, et al. Age at first birth and breast cancer risk. Bull World Health Organ 1970;43(2):209-21.

[7] Das S, Gokarn AG. A case-control study of carcinoma breast among women: an epidemiological risk factor study. Med Journal Armed Forces India 1995;51(4):237-40.

[8] Sharma JD, Kataki AC, Barman D, et al. Cancer statistics in Kamrup urban district: incidence and mortality in 2007-2011. Indian J Cancer 2016;53(4):600-6.

[9] Sen AK, Gupta DTK. Cancer of the breast and its treatment. Indian J Surg 1982: p. 833-47.

[10] Collaborative Group on Hormonal Factors in Breast Cancer CG on HF in B. Menarche, menopause and breast cancer risk: individual participant metaanalysis, including 118964 women with breast cancer from 117 epidemiological studies. Lancet Oncol 2012;13(11):1141-51.

[11] Katz A, Strom EA, Buchholz TA, et al. Locoregional recurrence patterns after mastectomy and doxorubicin-based chemotherapy: implications for postoperative irradiation. J Clin Oncol 2000;18(15):2817-27.

[12] Li CI, Daling JR, Malone KE. Incidence of invasive breast cancer by hormone receptor status from 1992 to 1998. J Clin Oncol 2003;21(1):28-34.

[13] Bauer KR, Brown M, Cress RD, et al. Descriptive analysis of estrogen receptor (ER)-negative, progesterone receptor (PR)-negative, and HER2negative invasive breast cancer, the so-called triplenegative phenotype. A population based study from the California cancer Registry. Cancer 2007;109(9):1721-8. 